\title{
EVALUASI WAKTU TUNGGU PELAYANAN RESEP RACIKAN POLI SPESIALIS ANAK PASIEN BPJS DI RUMAH SAKIT MEDIKA DRAMAGA BOGOR
}

\author{
Muhammad Afqary ${ }^{1 *}$, Dewi Wiyanti ${ }^{1}$, Inda Firliah ${ }^{2}$ \\ ${ }^{1}$ Program Studi S1 Farmasi Sekolah Tinggi Teknologi Industri dan Farmasi Bogor \\ ${ }^{2}$ RS Medika Dramaga, Bogor \\ *Korespondensi: afqary@gmail.com
}

\begin{abstract}
ABSTRAK
Pelayanan farmasi merupakan salah satu pelayanan kesehatan di rumah sakit yang diharapkan memenuhi standard pelayanan minimal. Sehingga salah satu cara untuk memenuhi standar pelayanan minimal adalah menyesuaikan ketepatan pelayanan kefarmasian dengan standar pelayanan minimal yang telah ditetapkan pemerintah. Waktu tunggu pelayanan obat racikan adalah tenggang waktu mulai pasien menyerahkan resep sampai dengan menerima obat racikan dengan standar minimal yang ditetapkan $\leq 60$ menit. Tujuan dilakukan penelitian ini adalah Untuk mengetahui faktor yang menjadi penyebab lamanya pelayanan resep BPJS racikan poli anak di RS Medika Dramaga Bogor. Penelitian ini merupakan penelitian survei dengan Menggunakan pendekatan kuantitatif dan didukung dengan kualitatif Hasil penelitian didapatkan rata-rata waktu tunggu pelayanan resep racikan di poli anak RS Medika Dramaga Bogor dengan sampel 134 lembar resep racikan dokter spesialis anak yaitu 62,29 menit terdiri dari jenis racikan: puyer, kapsul, sirup dan salep. Hal ini belum memenuhi Keputusan Menteri Kesehatan No.129/Menkes/SK/II/2008.
\end{abstract}

Kata kunci: waktu tunggu, pelayanan resep racikan poli anak, instalasi farmasi rumah sakit

\begin{abstract}
Pharmacy services are one of the health services in hospitals that are expected to meet minimum service standards. So that one way to meet minimum service standards is to adjust the accuracy of pharmaceutical services with minimum service standards set by the government. The waiting time for concoction services is the time for patients to submit their prescriptions to receive concoction drugs with a minimum standard set of $\leq 60$ minutes. The purpose of this study was to find out the factors that caused the length of prescription services for BPJS poly pediatric concoctions at the Medika Dramaga Hospital, Bogor. This research is a survey research using a quantitative approach and supported by qualitative. The results showed that the average waiting time for concoction prescription services at the Dramaga Medika Hospital in Bogor with a sample of 134 sheets of pediatrician's prescription concoction of 62.29 minutes consisted of: powder, capsules, syrup and ointment. This has not fulfilled the Decree of the Minister of Health No.129 / Menkes / SK / II / 2008.
\end{abstract}

Keywords: waiting time, child poly concoction recipe service, hospital pharmacy installation 


\section{PENDAHULUAN}

Rumah sakit adalah sarana kesehatan yang menyelenggarakan pelayanan kesehatan perorangan meliputi pelayanan promotif, preventif, kuratif dan rehabilitatif yang menyediakan pelayanan rawat inap, rawat jalan, dan gawat darurat. Rumah sakit sebagai salah satu fasilitas perayanan kesehatan perorangan merupakan bagian dari sumber daya kesehatan yang sangat diperlukan dalam mendukung penyelenggaraan upaya kesehatan. Penyelenggaran pelayanan kesehatan di rumah sakit mempunyai karakteristik dan organisasi yang sangat kompleks. Berbagai jenis tenaga kesehatan dengan perangkat keilmuan yang beragam, berinteraksi satu sama lain. Ilmu pengetahuan dan teknologi kedokteran yang berkembang sangat pesat yang perlu diikuti oleh tenaga kesehatan dalam rangka pemberian pelayanan yang bermutu standar, membuat semakin kompleksnya permasalahan di rumah sakit.

Pelayanan farmasi merupakan salah satu pelayanan kesehatan di rumah sakit yang diharapkan memenuhi standar pelayanan minimal. Sehingga salah satu cara untuk memenuhi standar pelayanan minimal adalah menyesuaikan ketepatan pelayanan kefarmasian dengan standar pelayanan minimal yang telah ditetapkan pemerintah. Dalam standar pelayanan minimal rumah sakit untuk pelayanan farmasi salah satunya adalah waktu tunggu pelayanan obat jadi (non racikan) dan racikan di instalasi farmasi (Kepmenkes RI, 2008).

Waktu tunggu pelayanan farmasi terbagi menjadi 2 (dua), yaitu waktu tunggu pelayanan obat jadi (non racikan) dan waktu tunggu pelayanan obat racikan. Waktu tunggu obat jadi (non racikan) adalah tenggang waktu mulai pasien menyerahkan resep sampai dengan menerima obat jadi (non racikan) dengan standar minimal yang ditetapkan $\leq 30$ menit. Sedangkan waktu tunggu pelayanan obat racikan adalah tenggang waktu mulai pasien menyerahkan resep sampai dengan menerima obat racikan dengan standar minimal yang ditetapkan $\leq 60$ menit (Kepmenkes RI,2008).

Waktu tunggu pelayanan farmasi terbagi menjadi 2 (dua), yaitu waktu tunggu pelayanan obat jadi (non racikan) dan waktu tunggu pelayanan obat racikan. Waktu tunggu obat jadi (nonracikan)adalah tenggang waktu mulai pasien menyerahkan resep sampai dengan menerima obat jadi (non racikan) dengan standar minimal yang ditetapkan $\leq 30$ menit. Sedangkan waktu tunggu pelayanan obat racikan adalah tenggang waktu mulai pasien menyerahkan resep sampai dengan menerima obat racikan dengan standar minimal yang ditetapkan $\leq 60$ menit (Kepmenkes RI, 2008).

Instalasi Farmasi Rumah Sakit adalah suatu bagian/unit/divisi atau fasilitas di rumah sakit, tempat penyelenggaraan semua kegiatan pekerjaan kefarmasian yang ditujukan untuk keperluan rumah sakit itu sendiri (Septini, 2012). Instalasi farmasi adalah unit pelaksana fungsional yang menyelenggarakan seluruh kegiatan pelayanan kefarmasian di Rumah Sakit (Menkes, 2016). Instalasi Farmasi Rumah Sakit Secara Umum dapat diartikan sebagai suatu departemen atau unit atau bagian di suatu rumah sakit di bawah pimpinan seorang apoteker dan dibantu oleh beberapa orang apoteker yang memenuhi persyaratan perundang-undangan yang berlaku dan bertanggung jawab atas seluruh pekerjaan serta kefarmasian, yang terdiri dari pelayanan yang mencakup perencanaan, pengadaan, produksi, penyimpanan perbekalan kesehatan/sediaan farmasi, dispensing obat berdasarkan resep bagi penderita saat tinggal dan rawat jalan, pengendalian mutu dan pengendalian distribusi dan penggunaan seluruh perbekalan kesehatan di rumah sakit. Pelayanan farmasi klinik umum dan spesialis mencakup pelayanan langsung pada penderita dan pelayanan klinik yang merupakan program rumah sakit secara keseluruhan (Septini, 2012).

\section{METODE PENELITIAN \\ Desain Penelitian}

Penelitian ini merupakan penelitian survei dengan Menggunakan pendekatan kuantitatif dan didukung dengan kualitatif. Metode kuantitatif digunakan dalam pengamatan jumlah waktu tunggu dalam menyelesaikan resep. Penelitian kualitatif dengan melakukan pengamatan langsung, dan dengan rancangan deskriptif Observasional terhadap pasien BPJS rawat jalan yang menebus resep di Instalasi Farmasi Rumah Sakit Medika Dramaga Bogor dan cara pengambilan sampel dengan menggunakan purpose sampling. Waktu penelitian ini yaitu pada bulan November 2019 - Januari 2019.

Penelitian ini dilakukan dengan menghitung waktu tunggu pelayanan resep obat racikan pada dokter spesialis anak kemudian dilakukan analisis terhadap kesesuaian dengan Standar Pelayanan Minmal Rumah Sakit 
kategori lama waktu tunggu.

Populasi dan Sampel

Populasi dari penelitian ini adalah seluruh Resep BPJS racikan dokter spesialis anak Pasien Rawat Jalan Rumah Sakit Medika Dramaga Bogor. Dengan Rata-rata perbulan 200 lembar Resep racikan dokter spesialis anak.

Sampel dalam penelitian ini adalah Resep Pasien BPJS Rawat Jalan yang memenuhi Kriteria Inklusi. Sampel diambil menggunakan Metode purposive sampling dan menggunakan Rumus slovin (sevilla et. Al., 1960:82) sebagai berikut:

$$
n=\frac{N}{1+N e^{2}}
$$

Dimana :

$\mathrm{n}=$ jumlah sampel

$\mathrm{N}=$ jumlah populasi

$1=$ konstanta

$\mathrm{E}=$ toleransi kesalahan $(0,05)^{2}$

Jumlah populasi pasien rawat jalan sebanyak maka jumlah sampel adalah :

$n=200$
$1+(0,05)^{2}=134$

Berdasarkan hasil perhitungan tersebut jumlah sampel minimal yang diperlukanadalah sebesar 134 lembar Resep racikan dokter spesialis anak.

\section{Kriteria Inklusi dan Eksklusi}

A. Kriteria inklusi:

1) Resep anak yang menggunakan BPJS yang terdaftar di poli rawat jalan di Rumah Sakit Medika Dramaga Bogor.

2) Resep racikan dokter poli spesialis anak.

B. Kriteriaekslusi:

1) Pasien yang obatnya tidak tersedia di InstalasiFarmasi..

2) Pasien yang obatnya tidak diambil.

Sumber dan Metode pengumpulan data penelitian

1. Data Penelitian Kuantitatif:

a. Data primer

Dikumpulkan melalui pengamatan langsung dan pencatatan waktu tunggu pelayanan resep dalam formulir pencatatan waktu tunggu.

b. Data sekunder

Data yang didapatkan dari Rumah Sakit Medika Dramaga Bogor berupa telaah dokumen Standar Operasional Prosedur pelayanan BPJS rawat jalan, jumlah ketenagaan.

\section{Teknik Pengumpulan Data}

Alat yang digunakan untuk pengumpulan data kuantitatif berupa formulir pencatatan waktu tunggu, stopwatch dan alat tulis. Pengamatan dilakukan dengan pengamatan langsung resep pasien BPJS dokter spesialis anak yang masuk setiap hari Senin sampai dengan Sabtu, Kemudian dihitung waktu pelayanan resep dengan menggunakan stopwatch pada tiap titik yang membagi proses pelayanan menjadi komponen tindakan dan komponen delay.

Hasil pengukuran waktu tersebut dimasukkan ke dalam waktu tunggu. Alat yang digunakan dalam menentukan data kualitatif adalah wawancara pada informan sebagai narasumber, hasil wawancara yang dilakukan kemudian dicatat. Pengumpulan data sekunder diperoleh dengan penelusuran dokumen yang ada di Rumah Sakit Medika Dramaga Bogor.

\section{Analisis Data}

Penilaian kecepatan pelayanan resep ini dikatakan memenuhi persyaratan Keputusan Menteri Kesehatan Republik Indonesia Nomor 129 tahun 2008 tentang Standar Pelayanan Minimal Rumah Sakit apabila : Untuk resep obat racikan, memenuhi persyaratan kecepatan waktu pelayanan $\leq 60$ menit.

Untuk data yang diperoleh dari pencatatan tiap titik alur proses pelayanan farmasi yang diperoleh dirubah ke dalam satuan menit kemudian dengan menggunakaan statistik dihitung nilai mean, median, dan standar devisiasi pada titik tiap alur resep. Pengolahan data yang dilakukan dengan menganalisis hasil pengamatan serta jawaban wawancara mendalam dengan informan.

1. Mengumpulkan semua data yang diperoleh dari berbagai sumber baik data yang di dapat dari wawancara mendalam, pengamatan maupun telaah dokumen.

2. Menyajikan ringkasan data dalam bentuk matriks.

3. Mengelompokan data kedalam kategorikategori tertentu dengan tujuan untuk mengorganisasi sehingga data dapat memunculkan gambaran tentang topik yang 
71 Muhammad Afqary et al., (Evaluasi Waktu Tunggu Pelayanan Resep...)

diamati.

4. Melakukan penyajian data yang berupa kumpulan informasi yang sudah teroganisir dan memberikan gambaran tentang hasil penelitian.

\section{HASIL DAN PEMBAHASAN Karakteristik Resep}

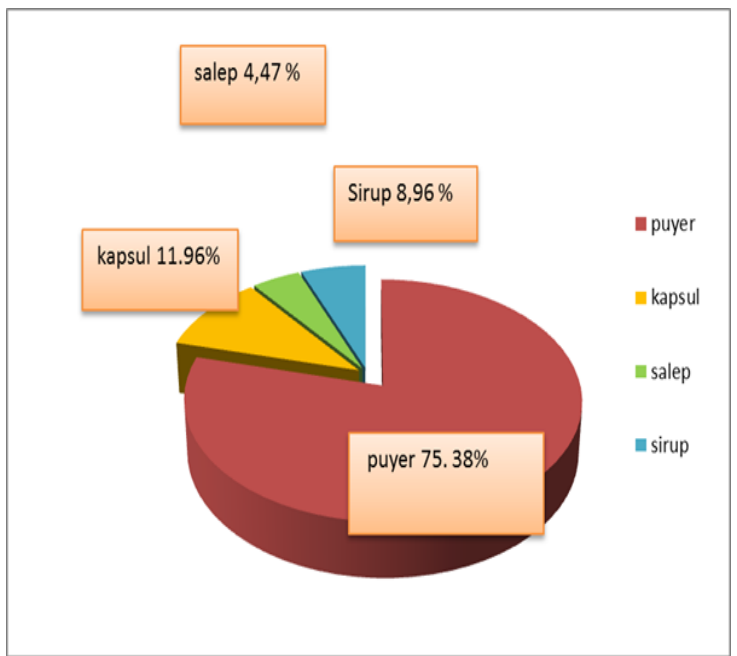

Gambar 1. Data waktu tunggu pelayanan resep berdasarkan jenis racikan

Dari hasil penelitian didapat jumlah sampel dalam penelitian ini sebanyak 134 lembar resep, terdiri dari resep racikan puyer, kapsul, salep, dan sirup.

Waktu tunggu secara umum dari 134 sampel lembar resep adalah 62.29menit, dengan range 10.00 menit sampai 149.54 standar deviasi 23.78 menit dan median 55.38 menit. Perbedaan rerata dan median menunjukan waktu yang tidak terdistribusi normal, tetapi hampir memenuhi SPM pelaksanaan pelayanan rumah sakit.

Tabel 1. Waktu Tunggu Pelayanan Resep racikan

\begin{tabular}{|l|c|c|c|c|c|}
\hline $\begin{array}{l}\text { Jenis } \\
\text { Racikan }\end{array}$ & stdev & median & average & $\min$ & $\max$ \\
\hline Puyer & 0.61 & 1.33 & 1.37 & 0.15 & 3.21 \\
\hline Kapsul & 0.73 & 0.73 & 1.43 & 0.15 & 2.45 \\
\hline Sirup & 0.49 & 0.31 & 0.66 & 0.24 & 1.44 \\
\hline Salep & 0.9 & 1.56 & 1.44 & 0.15 & 2.45 \\
\hline
\end{tabular}

Berdasarkan data diatas bahwa lebih cepat mengerjakan resep racikan sirup dibanding jenis racikan lainnya.

Tabel 2. Rerata Total Waktu Tunggu Dari Seluruh Sampel Resep Racikan Dalam Menit

\begin{tabular}{|l|l|}
\hline Rerata & Menit \\
\hline Stdev & 23.78 menit \\
\hline Median & 55.38 menit \\
\hline Min & 10.00 menit \\
\hline Max & 149.54 menit \\
\hline N & 134 \\
\hline
\end{tabular}

Tabel 3. Waktu Tunggu Pelayanan Resep racikan

\begin{tabular}{|l|r|r|c|c|c|}
\hline \multirow{2}{*}{ Hari } & \multirow{2}{*}{ Total } & \multicolumn{5}{|c|}{ Jenis Resep Racikan } \\
\cline { 3 - 6 } & & Puyer & Kapsul & Salep & Sirup \\
\hline Senin & 26 & 16 & 7 & 0 & 3 \\
\hline $\begin{array}{l}\text { Selas } \\
\text { a }\end{array}$ & 15 & 7 & 4 & 1 & 3 \\
\hline Rabu & 12 & 9 & 1 & 1 & 1 \\
\hline $\begin{array}{l}\text { Kami } \\
\text { s }\end{array}$ & 21 & 17 & 1 & 1 & 1 \\
\hline Jumat & 24 & 22 & 1 & 1 & 0 \\
\hline Sabtu & 36 & 29 & 1 & 2 & 4 \\
\hline Total & 134 & 10 & 15 & 6 & 12 \\
\hline
\end{tabular}

Dari Tabel 3. Di atas disimpulkan bahwa resep racikan terbanyak terjadi pada hari sabtu sebanyak 36 lembar resep racikan dokter spesialis anak.

Salah satu faktor utama yang mempengaruhi lamanya waktu tunggu pelayanan resep di Instalasi Farmasi terdapat tiga fase yaitu fase pertama adalah saat penerimaan resep. Penerimaan resep di lakukan oleh kasir setelah pasien berobat lalu pasien menukar resep dengan nomor antrian obat di kasir, lalu kasir memberikan resep di loket apotek, setelah itu terjadi proses penginputan resep setelah diinput lalu resep di telaah dan disiapkan oleh petugas farmasi setidaknya 1 orang yang menyiapkan resep, pada proses ini dibutuhkan pengetahuan petugas untuk mengetahui letak penyimpanan obat, Kemudian obat yang telah disiapkan di racik dan diberi etiket.

Pada proses pemberian etiket proses ini 
72 | Muhammad Afqary et al., (Evaluasi Waktu Tunggu Pelayanan Resep...)

membutuhkan keterampilan petugas agar cepat dalam menulis dan menempel etiket obat setelah obat diambil atau diracik, memeriksa kembali kesesuaian obat dengan resep serta membuat copy resep jika diperlukan. setelah proses selesai dilakukan pengecekan terlebih dahulu sebelum diserahkan kepada pasien tersebut. Fase kedua adalah saat penyiapan obat karena dilakukan oleh satu orang, dan fase ketiga pada proses peracikan kurangnya sarana dan prasarana yaitu blender yang rusak sehingga harus mengerjakan obat racikan dengan cara manual dan kurangnya fasilitas komputer untuk menginput resep.

\section{SIMPULAN}

Berdasarkan uraian pembahasan dapat disimpulkan bahwa:

1. Faktor penyebab lamanya waktu tunggu pada pelayanan resep racikan dokter spesialis anak adalah:

a. Masih adanya kekosongan obat dipertengahan waktu pelayanan, sehingga harus menunggu mengambil obat di gudang, di apotek eksekutif dan apotek rawat inap.

b. Masih adanya kekosongan obat dipertengahan waktu pelayanan, sehingga petugas harus mengkonfirmasi obat terlebih dahulu kepada dokter untuk diganti obat dengan obat yang ada di instalasi farmasi rawat jalan.

c. Program komputer atau sistem yang belum sempurna terkadang komputer eror dan tinta alat print yang eror menyebabkan proses pada penginputan resep obat menjadi lama.

d. Kurangnya jumlah tenaga kefarmasian saat bertugas sehingga proses waktu penyiapan resep meningkat.

2. Gambaran waktu tunggu pelayanan resep racikan dokter di poli anak melebihi standar waktu yang telah ditetapkan oleh kepmenkes No.129/Menkes/SKII/2008 yaitu sebesar 62,67 menit untuk resepracikan. Seharusnya standar pelayanan minimal untuk pengerjaan obat racikan $\leq 60$ menit. Hal ini menunjukan bahwa rata-rata waktu tunggu pelayanan resep di instalasi farmasi pasien rawat jalan Rumah Sakit Medika Dramaga Bogor belum memenuhi standar pelayanan minimal.

\section{DAFTAR PUSTAKA}

[1] Keputusan Menteri Kesehatan (Kepmenkes) Republik Indonesia Nomor: 129/Menkes/SKII/2008 tentang Standar Pelayanan Minimal Rumah Sakit. Jakarta : DepkesRI

[2] Seville, et all. 1960. Pengantar Metode Penelitian. Jakarta : Universitas Indonesia.

[3] Septini, R. 2012. Analisis Waktu Tunggu Pelayanan Resep Pasien Askes Rawat Jalan di Yanmasum Farmasi RSPAD Gatot Subroto tahun 2011. Tesis. Depok: Fakultas Kesehatan Masyarakat. Halaman 07-35.

[4] Kemkes, RI. 2016. Peraturan Menteri Kesehatan Republik Indonesia Nomor 72 Tahun 2016 Tentang Standar Pelayanan Kefarmasian Di Rumah Sakit. Jakarta: Departemen Kesehatan RI. Halaman 11 40. 